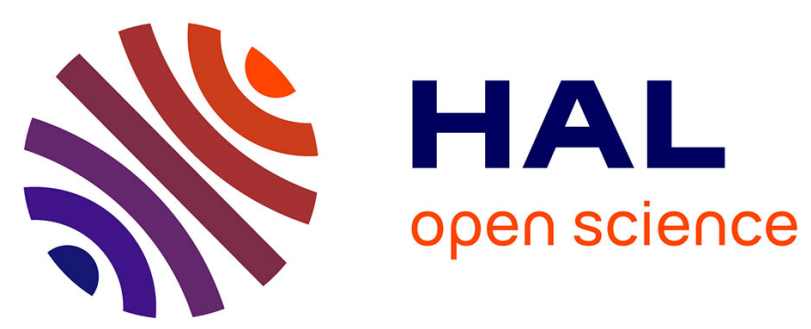

\title{
A Real-Time Adjustment Method of Conventional Under-Frequency Load Shedding Thresholds
}

Barnabé Potel, Vincent Debusschere, Florent Cadoux, Urban Rudez

\section{To cite this version:}

Barnabé Potel, Vincent Debusschere, Florent Cadoux, Urban Rudez. A Real-Time Adjustment Method of Conventional Under-Frequency Load Shedding Thresholds. IEEE Transactions on Power Delivery, 2019, 10.1109/TPWRD.2019.2900594 . hal-02268568

\section{HAL Id: hal-02268568 https://hal.science/hal-02268568}

Submitted on 21 Aug 2019

HAL is a multi-disciplinary open access archive for the deposit and dissemination of scientific research documents, whether they are published or not. The documents may come from teaching and research institutions in France or abroad, or from public or private research centers.
L'archive ouverte pluridisciplinaire HAL, est destinée au dépôt et à la diffusion de documents scientifiques de niveau recherche, publiés ou non, émanant des établissements d'enseignement et de recherche français ou étrangers, des laboratoires publics ou privés. 


\title{
A Real-Time Adjustment of Conventional Under-Frequency Load Shedding Thresholds
}

\author{
Barnabé Potel, Vincent Debusschere, Member, IEEE, Florent Cadoux and Urban Rudez, Member, IEEE
}

\begin{abstract}
This letter presents an innovative and easy-toimplement approach for improvement of conventional underfrequency load shedding, where frequency thresholds are adjusted locally in real-time. The proposed method, that would be implemented locally in each under-frequency relay, estimates the forthcoming frequency evolution and adjusts the predefined frequency thresholds values according to the estimated frequency nadir. As a result, significantly improved frequency response by reducing overshoots can be observed. Concept verification was performed by means of Slovenian power-system model simulations, where the comparison with conventional constantthreshold setting showed high level of efficiency.
\end{abstract}

Index Terms-Power system stability, relays, underfrequency load shedding.

\section{INTRODUCTION}

$\mathbf{U}$ NDER-FREQUENCY load shedding (UFLS) protection is the last resort to prevent a total black-out of the electrical power system (EPS) after major active power imbalance appears. To ensure a reliable UFLS operation, it is essential to make it highly robust, which means i) to shed sufficient load for containing the frequency decrease and ii) to avoid over-shedding as it can lead to an over-frequency situation. Generally, conventional settings satisfy only the first criterion.

The concept of predicting the forthcoming frequency evolution has already been studied in a centralized manner using WAMS [1]. In this letter, we implement this prediction locally. It is based on a second-order polynomial fitting that reveals the expected frequency nadir, which is used as a parameter to update the frequency thresholds. Such use of multi-criteria is common in the UFLS literature where apart from frequency additional parameters might be the Rate of Change of Frequency (RoCoF) [2] and voltage [3] alone or even both at the same time [4].

\section{Method Description}

\section{A. Polynomial fitting and adjustment principle}

The frequency prediction is realized with a second-order polynomial, $\hat{f}_{i}(t)$, expressed as follows at instant $i$ :

$$
\hat{f}_{i}(t)=a \cdot t^{2}+b \cdot t+c
$$

The work reported in this letter has been achieved in the framework of the Enedis Industrial Research Chair on Smart Grids and supported by a Slovenian Research Agency as a part of the research program Electric Power Systems (P2-356) and Resource management for low latency reliable communications in smart grids - LoLaG (J2-9232).

B. Potel, V. Debusschere and F. Cadoux are with Univ. Grenoble Alpes, CNRS, Grenoble INP, G2Elab, 38000 Grenoble, France (e-mail: barnabe.potel@g2elab.grenoble-inp.fr; vincent.debusschere@g2elab.grenobleinp.fr; florent.cadoux@g2elab.grenoble-inp.fr).

U. Rudez is with the Faculty of Electrical Engineering, University of Ljubljana, Ljubljana 1000, Slovenia (e-mail: urban.rudez@fe.uni-lj.si).
The parameters $a, b$ and $c$ are determined by minimizing the square error between the polynomial function and the frequency measurements, which is a straightforward procedure from the implementation point of view (e.g. to protection relay). Even though in theory a three-parameter function like (1) requires a minimum of three frequency samples, taking a greater number ensures a more robust approximation considering measurement inaccuracies.

If the minimum value of the polynomial approximation (1) exists (calculated from the value of the discriminant) it represents the expected frequency nadir denoted by $f_{\min }$. Fig. 1 shows a polynomial approximation of the frequency at a specific instant and the associated frequency nadir.

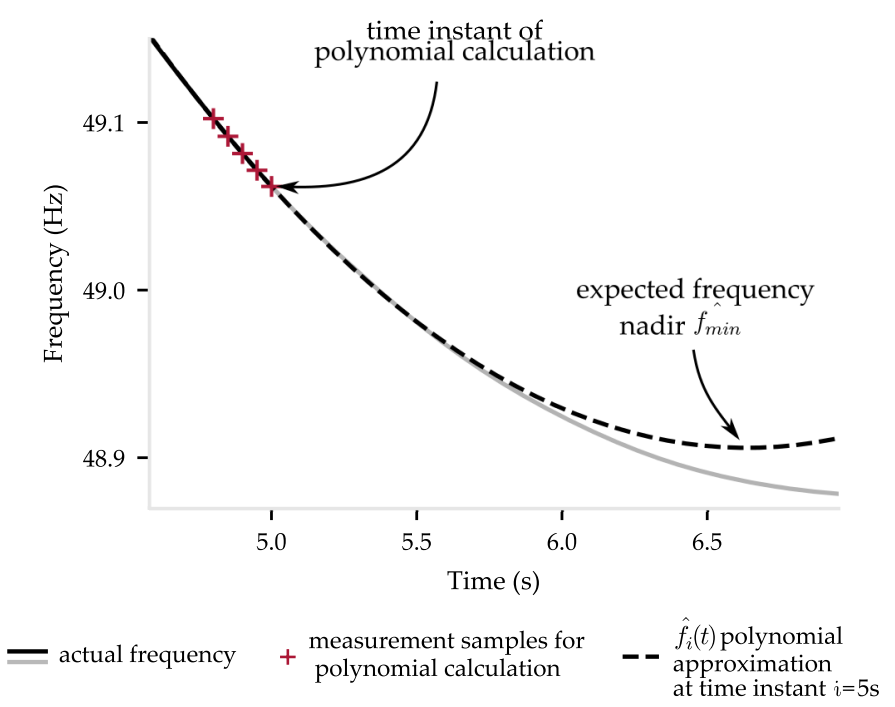

Fig. 1. Second-order polynomial approximation of the frequency.

Once $\hat{f_{\min }}$ is calculated at the instant $i$, this value is used to adjust the frequency thresholds of different steps for the instant $i+1$. This adjustment is done according to the need whether step activation is already needed or not: if $\hat{f_{\min }}$ is calculated lower than the minimum step-threshold value, the corresponding step is forced to activate earlier by increasing the corresponding threshold. This allows to stop the frequency decreasing sooner. Conversely, if $\hat{f_{\min }}$ is expected greater than the minimum step-threshold value, the corresponding step is delayed by decreasing the threshold, as there appears no need to shed the step so early.

\section{B. Scheme implementation}

The implemented method is limited to make only minor adjustments to pre-set frequency thresholds and guarantees the 
step discrimination by imposing a minimum frequency distance between two consecutive steps. This minimum distance, denoted $\Delta f_{t h r}$, depends directly on the EPS characteristics and a protection device: the latter should have enough time to trigger when a frequency threshold is violated before reaching the next threshold - for small imbalances. In the studied case, the minimum distance between two dynamic frequency thresholds is fixed to be $150 \mathrm{mHz}$.

To incorporate consequences of step activation in the polynomial approximation (which is updated at every instant), the time delay between two consecutive frequency samples must not be too large. In this letter it was selected to be $40 \mathrm{~ms}$ (five frequency samples within assumed $200 \mathrm{~ms}$ time between frequency-threshold violation itself and the successful opening of the circuit breaker). Such assumption makes the approach able to take into account several consecutive steps activation in case of a large initial imbalance as well.

Table I encompasses the parameters of both conventional and presented schemes settings. The conventional scheme is a compliant scheme of the current grid code [5].

TABLE I

CONVENTIONAL (STATIC) AND PREDICTIVE (DYNAMIC) SETTINGS.

\begin{tabular}{|c|c|c|c|c|c|c|}
\hline Step & 1 & 2 & 3 & 4 & 5 & 6 \\
\hline Load shed $(\%)$ & 7.5 & 7.5 & 7.5 & 7.5 & 7.5 & 7.5 \\
\hline Static thresholds $(\mathrm{Hz})$ & 49 & 48.8 & 48.6 & 48.4 & 48.2 & 48 \\
\hline Dyr & \multicolumn{6}{|c|}{ Adaptive thresholds for predictive method } \\
\hline Maximal frequency $(\mathrm{Hz})$ & 49 & 48.85 & 48.7 & 48.55 & 48.4 & 48.25 \\
\hline Minimal frequency $(\mathrm{Hz})$ & 48.75 & 48.6 & 48.45 & 48.3 & 48.15 & 48 \\
\hline
\end{tabular}

\section{Frequency thresholds adjustment in real time}

At each time step $i$, the frequency thresholds are updated according to the difference between the minimal values they are allowed to reach and the expected frequency nadir:

$$
\begin{aligned}
& \delta f_{n_{i}}= K_{i} \times\left(f_{n_{\min }}-\hat{f_{\min _{i}}}\right) \\
& f_{n_{i+1}}=\left\{\begin{array}{l}
f_{n_{i}}+\delta f_{\max } \text { if } \delta f_{n_{i}}>\delta f_{\max } \\
f_{n_{i}}-\delta f_{\max } \text { if } \delta f_{n_{i}}<-\delta f_{\max } \\
f_{n_{i}}+\delta f_{n_{i}} \text { otherwise }
\end{array}\right.
\end{aligned}
$$

subject to $f_{n_{\min }} \leq f_{n_{i+1}} \leq f_{n_{\max }}$

$$
\text { and } f_{n_{i+1}} \leq f_{n-1_{i+1}}-\Delta f_{t h r}, \quad \forall n \in \llbracket 2,6 \rrbracket
$$

$K_{i} \quad$ is the integration coefficient.

$f_{\text {min }_{i}}$ is the estimated frequency nadir with the polynomial fitting at instant $i$, as shown in Fig. 1.

$f_{n_{i}} \quad$ is the frequency threshold of step $n$ at instant $i$.

$f_{n_{\min }}, f_{n_{\max }}$ are the frequency boundaries of the step $n$ as described in Table I.

$\delta f_{\text {max }}$ is the maximum change of the frequency thresholds between two calculation samples.

The boundary $\delta f_{\max }$ - here fixed to reach a maximum of $0.5 \mathrm{~Hz} / \mathrm{s}$ for the threshold update - is chosen slightly greater than the deviation of the RoCoF produced by the shedding of a step - depending on the inertia of the EPS and the load shed per step. The controlled rate $K_{i}$ allows a smoother update of the thresholds if the frequency nadir is close to the minimal frequency - to avoid zig-zag updates of the thresholds. Its value combined with $\delta f_{\max }$ gives the frequency range where the thresholds are updated proportionally according to (2). This frequency range - chosen here at $\pm 10 \mathrm{mHz}$ - corresponds indirectly to the precision in the frequency nadir calculation.

Using a controlled rate $K_{i}$ and a boundary $\delta f_{\max }$ allows us to limit the impact of degraded measurements and calculations. Moreover, i) even if the prediction returns wrong values, the steps are still discriminated by their minimum and maximum allowed spread; and ii) as the polynomial approximations are different across the EPS, some parts of the system may shed a certain step sooner while others a bit later: this virtually introduces additional steps, which even further decreases the risk of over-shedding and consequently of over-frequency.

\section{RESULTS}

Conventional and predictive methods are implemented in a dynamic model of a part of the Slovenian EPS. Fig. 2 shows the frequency evolution and thresholds for both methods.

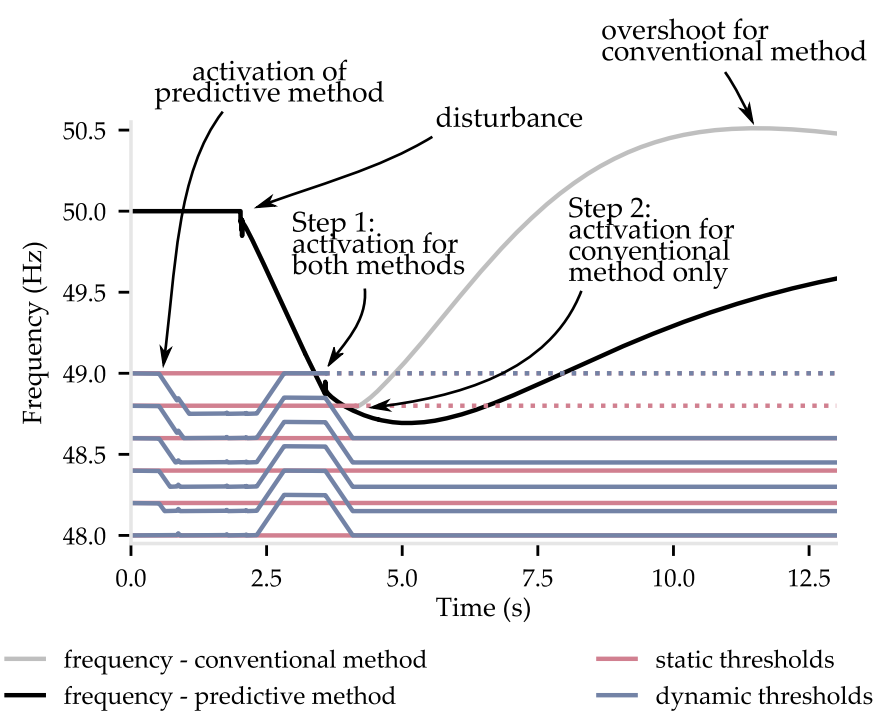

Fig. 2. Frequency evolution at a selected node for both conventional and the predictive approach, power imbalance of $14 \%$.

The frequency evolution before reaching the $49 \mathrm{~Hz}$ is the same for both methods. The conventional method having static thresholds activates two steps which implies an overshoot in the frequency (grey curve). The predictive method activates a single step, which results in improved frequency response (frequency within satisfactory boundaries - black curve) and at the same time limits the economical impact of shedding by keeping more load supplied [6].

Initially, thresholds of both methods are identical. Once the presented method is activated, the dynamic thresholds are decreasing until they reach their lower boundaries. After a disturbance occurs, the dynamic thresholds are increasing for a small period of time, as the approximation fully captures the new frequency trend, until they finally reach their upper boundaries. After the first step activation, the prediction foresees the expected nadir to be greater than the lower boundary 
of the second step. Thus, all the dynamic thresholds are decreasing down to their lower boundaries.

\section{CONCLUSion}

The proposed approach supports the existing robustness of the conventional UFLS scheme by keeping the principles of steps. Furthermore, the possible adjustments of frequency thresholds increases the robustness by giving the opportunity to improve the frequency response and reduce the total load shed. Like the conventional method, calculations are realized locally, so the implementation of the method can be realized within a set of existing relays. By appropriately setting the threshold boundaries, potentially incorrect predictions have no negative consequences on UFLS operation. At this stage of research, simulations indicate a high potential of the method.

\section{REFERENCES}

[1] U. Rudez and R. Mihalic, "WAMS-Based Underfrequency Load Shedding With Short-Term Frequency Prediction," in IEEE Transactions on Power Delivery, vol. 31, no. 4, pp. 1912-1920, Aug. 2016.

[2] V. V. Terzija, "Adaptive underfrequency load shedding based on the magnitude of the disturbance estimation," in IEEE Transactions on Power Systems, vol. 21, no. 3, pp. 1260-1266, Aug. 2006.

[3] B. Hoseinzadeh, F. M. Faria da Silva and C. L. Bak, "Adaptive Tuning of Frequency Thresholds Using Voltage Drop Data in Decentralized Load Shedding," in IEEE Transactions on Power Systems, vol. 30, no. 4, pp. 2055-2062, July 2015.

[4] A. Saffarian and M. Sanaye-Pasand, "Enhancement of Power System Stability Using Adaptive Combinational Load Shedding Methods," in IEEE Transactions on Power Systems, vol. 26, no. 3, pp. 1010-1020, Aug. 2011.

[5] ENTSO-E. Network Code on Emergency and Restoration, Dec. 2017.

[6] Power Blackout Risks, Risk Management Options, Emerging Risk Initiative Position Paper, November 2011 